\title{
$\mathrm{P}$
}

едкие проявления фолликулярного красного плоского лишая, возникшие в процессе егО ЭВОЛЮЦИИ

\author{
Е.В. Соколовский, Г.Н. Михеев, П.А. Резцова
}

ГБОУ ВПО «Первый Санкт-Петербургский государственный медицинский университет им. академика И.П. Павлова» Минздрава России

197022, Санкт-Петербург, ул. Льва Толстого, д. 6-8

Представлено клиническое наблюдение больного с длительно протекающей фолликулярной формой красного плоского лишая. В процессе его эволюции образовалась очаговая атрофия гладкой кожи. Приведены данные

литературы о клинических особенностях этой атипичной фрормы дерматоза.

Ключевые слова: фолликулярный красный плоский лишай, атрофия гладкой кожи.

Контактная инсоормация: polinavashkevich@gmail.com. Вестник дерматологии и венерологии 2016; (1): 63—68.

\section{Rare evidence of follicular lichen planus that arise in the process of its evolution}

\section{E.V. Sokolovskiy, G.N. Miheev, P.A. Reztsova}

First Pavlov State Medical University of St. Petersburg Lev Tolstoy str., 6/8, bldg 4, St. Petersburg, 197022, Russia

Case study of the patient with a follicular lichen planus long-flowing form was presented. In the process of its evolution there formed a focal atrophy of the smooth skin. This atypical form clinical features data is provided.

Key words: follicular lichen planus, skin smooth atrophy. 
Заболевание было описано в 1862 г., когда два авторитетных дерматолога независимо друг от друга описали фолликулярную разновидность папул при красном плоском лишае. E. Bazin назвал заболевание lichen pilaris par alteration fonctionnell, de la papille [1], a F. Hebra - lichen ruber acuminatus [2]. B 1869 г. E. Wilson дал подробную характеристику заболевания, описав варианты морфологии и преимущественной локализации высыпных элементов [3]. Однако в то время E. Wilson находился под влиянием авторитета F. Hebra и также рассматривал заболевание как вариант отрубевидного красного волосяного лишая (цит. по [4]).

После I Международного конгресса дерматологов в Париже (1889) было выяснено, что поражение кожи, описанное в 1896 г. М. Devergie как pityriasis rubra pilaris, ошибочно рассматривалось представителями венской школы (Kaposi) как разновидность красного плоского лишая под названием lichen ruber acuminatus. Вероятнее всего, ошибка была обусловлена идентичностью первичного высыпного элемента - фролликулярной остроконечной воспалительной папулы, которая возникает как при отрубевидном красном волосяном лишае, так и при фолликулярной форме красного плоского лишая. Как оказалось позднее, локализация, течение, гистологические изменения и эволюция фолликулярных папул при этих дерматозах различны. В частности, при красном отрубевидном волосяном лишае в месте разрешения фолликулярной папулы не остается рубцовой атрофиии ни на коже волосистой части головы, ни на гладкой коже, а элементы красного плоского лишая, в свою очередь, не склонны к слиянию и образованию обширных эритематосквамозных очагов вплоть до развития эритродермии. Позднее дерматологи пришли к единодушному выводу, что pityriasis rubra pilaris Devergie является отдельной нозологической формой.

В 1895 г. J. Pringle описал заболевание, впоследствии названное lichen planopilaris Pringle, представляющее собой сочетание остроконечных фролликулярных папул с типичными папулами красного плоского лишая [5]. Для описания клиники классического варианта красного плоского лишая используют мнемоническое правило «4 "Р"»: papule (папула), polygonal (полигональная), purple (фиолетовая), pruritic (зудящая). Известно, что в клинической картине lichen ruber follicularis доминируют остроконечные (не полигональные) телесного или розово-красного цвета (не фриолетовые) папулы, для которых зуд чаще всего не характерен. Другим значимым отличием фолликулярной формы является частый дебют на коже волосистой части головы, где эволюция папул всегда приводит к образованию очагов атрофии кожи (псевдопелады). Трудность диагностики фолликулярной формы lichen ruber planus обусловлена различающимися по морфологии первичными высыпными эле- ментами при атипичной (фолликулярной) и типичной фрормах этого дерматоза, а также отсутствием в ряде случаев сочетания фролликулярных папул с типичными нефолликулярными полигональными папулами одновременно.

Описанные особенности явились предпосылкой для выделения отдельного симптомокомплекса (1915 г.), названного по именам дерматологов, описавших их впервые, - Piccardi - Lassueur - Little [6, 7]. E. Little рассматривал комбинацию очагов рубцовой алопеции на коже волосистой части головы с клинически нерубцовым облысением лобка и подмышечных впадин в сочетании с фолликулярными папулами на гладкой коже как стадии эволюции одного дерматоза, дав ему название lichen spinulosus et folliculitis decalvans [8]. После наблюдения еще нескольких больных, у которых отмечались помимо фолликулярных еще и типичные для красного плоского лишая папулы, автор пришел к выводу о клиническом сходстве синдрома $\mathrm{c}$ lichen planopilaris Pringle [9]. В дальнейшем большинство авторов признали идентичность описанного синдрома и фолликулярной формы красного плоского лишая и присвоили определение «атрофический вариант красного плоского лишая с преимущественным поражением фролликулярного аппарата кожи» $[10,11]$.

В подмышечных впадинах и лобковой области облысение клинически воспринимается как нерубцовое. Тем не менее еще E. Little описывал алопецию на различных участках тела как рубцовую, а E. Traub выдвигал гипотезу о несоответствии клинически воспринимаемого нерубцового облысения гистологическим изменениям в волосяных фолликулах [8, 12]. И. М. Разнатовский и А.Н. Родионов (1978) обобщили данные литературы, дополнив их собственными наблюдениями, и подтвердили, что облысение на различных участках кожного покрова, покрытых длинными или пушковыми волосами, обусловлено прежде всего гибелью волоса в результате локального фриброзирования сально-волосяного фолликула без выраженных признаков атрофии эпидермиса, из-за чего алопеция клинически воспринимается как нерубцовая [13]. Имеются сообщения о поражении фолликулярной фрормой красного плоского лишая не только пушковых волос на туловище и конечностях, а также щетинистых волос в области бровей и ресниц, что подчеркивает универсальность поражения волосяных фолликулов [14-16].

В упомянутых наблюдениях, как и в исследованиях В.А. Молочкова и соавт. [17], у пациентов с фолликулярной формой красного плоского лишая отмечали поражение кожи волосистой части головы в виде очагов рубцовой алопеции различной степени выраженности. Давность существования высыпаний на гладкой коже (в тех случаях, где таковые изменения были описаны) составляла не более 5 лет. В подавляющем 
большинстве случаев фролликулярная форма красного плоского лишая дебютировала на коже волосистой части головы [12, 14].

Современные дерматологи при диагностике редко используют название «Piccardi - Lassueur — Little syndrome», так как в нем не отражена нозология дерматоза и нет сведений о клинических его проявлениях $[13,14,18]$

Представляем наблюдение больного с длительно существующей фолликулярной формой красного плоского лишая, с дебютом дерматоза на конечностях, своеобразной эволюцией элементов сыпи на гладкой коже с образованием крупных пестрых очагов с атрофией кожи (на бедрах) и без поражения кожи волосистой части головы, подмышечных и лобковой областей.

Пациент К., 62 года, болен с 2004 г., когда после обморожения кожи кистей рук и лица отметил появление стойкой эритемы. Впоследствии появились мелкие бессимптомные узелковые высыпания на коже бедер. Постепенно высыпания распространились на кожу плеч, предплечий и голеней. В 2006 г. обратился в Городской кожно-венерологический диспансер (КВД) г. Тихвина, где был поставлен диагноз псориаз и назначена терапия витамином $\mathrm{B}_{12}$ в сочетании с фолиевой кислотой и УФ-облучением кожи без значимого клинического эфффекта. Пациент был направлен на санаторно-курортное лечение в Алушту, где на фоне инсоляции и курса сероводородных ванн высыпания частично регрессировали. В 2009 г. в связи с повторным распространением высыпаний вновь обратился в КВД г. Тихвина, где с тем же диагнозом получал терапию пентоксифиллином и индиффрерентной мазью. Отмечал уменьшение кожных высыпаний до 2011 г. Впоследствии к дерматологам по поводу существовавшего поражения кожи не обращался. В марте 2015 г. по поводу хронической венозной недостаточности пациент был направлен на консультацию в клинику госпитальной хирургии ПСПбГМУ им. акад. И.П. Павлова, но в связи с распространенными папулезными высыпаниями был госпитализирован в клинику дерматовенерологии, где был заподозрен распространенный красный плоский лишай, фолликулярная фрорма.

При осмотре: общее состояние удовлетворительное, сознание ясное. Пациент гиперстенического телосложения, повышенного питания, рост $185 \mathrm{~cm}$, масса 136 кг. Высыпания распространенные и располагались на коже лица, кистей рук, предплечий, плеч, поясничной и ягодичной областей, коже бедер, голеней и стоп. Первичными элементами сыпи были мелкие фолликулярные воспалительные папулы, сгруппированные в области тыла кистей рук, запястий, разгибательной поверхности локтевых суставов и слившиеся в поясничной области справа, на бедрах и разгибательной поверхности коленных суставов в бляшки диаметром до 30 см с отдельными фолликулярными папулами по периферии. В области разгибательной поверхности локтевых суставов отмечались фолликулярно расположенные сгруппированные красно-коричневые папулы с выраженными остроконечными шипиками на вершинах (положительный симптом «терки»). На разгибательной поверхности пальцев, тыле кистей рук - многочисленные фолликулярные и перифолликулярные красно-бурые папулы с гиперкератозом на вершинах.

На коже поясницы справа - круглая слабоинфильтрированная бляшка фиолетового цвета диаметром 12 см с видимо гомогенной окраской и нечеткими границами. При диаскопии в периферической зоне выявились отдельные коричневатые точечные элементы. На передневнутренней поверхности бедер симметрично располагались пестрые слабоинфильтрированные очаги размером до 40 см мелкоячеистого строения, формирующие рисунок по типу медовых сот, образованный за счет чередования мелких депигментированных участков атрофии с участками более выраженной красно-коричневой окраски кожи и телеангиэктазиями (рис. 1). На левой нижней конечности

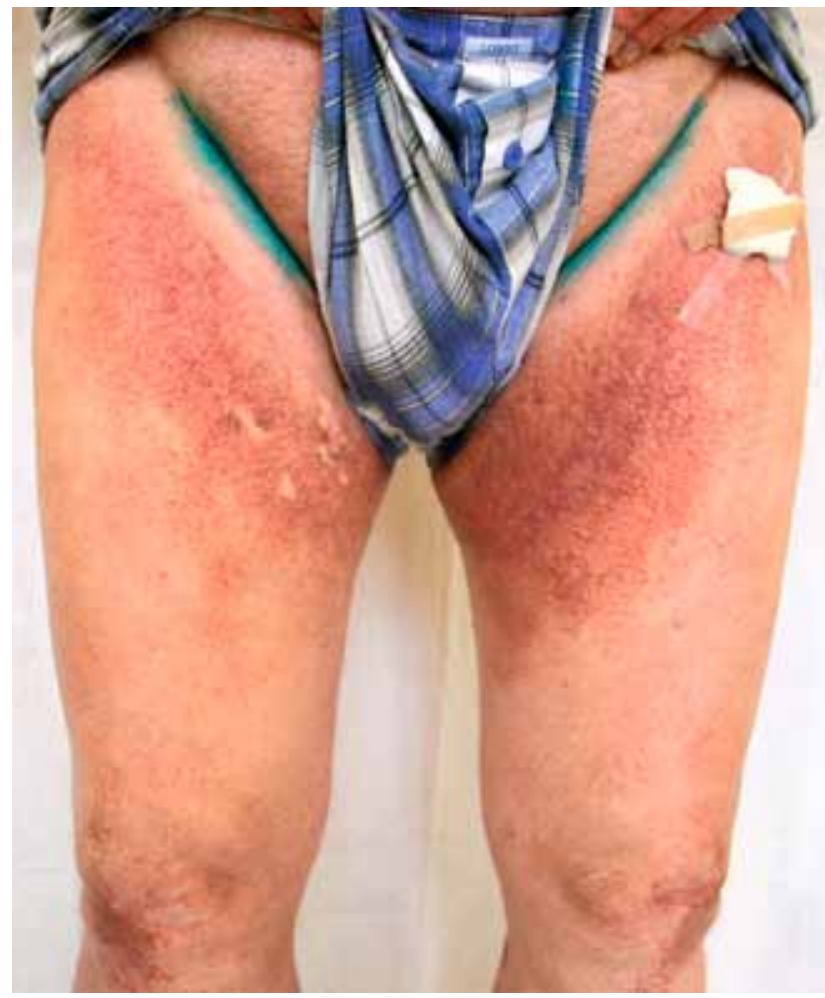

Очаги пойкилодермии с мелкоячеистым Рис. 1. строением. Видны белые участки атрофиии кожи и сгущения окраски красно-коричневого цвета с телеангиэктазиями 
очаг распространился на заднюю поверхность бедра. Преимущественно в пределах очага на передневнутренней поверхности левого бедра имелись участки более выраженной атрофии кожи неправильной фрормы размером до 2 см. На границе перехода в видимо неизмененную кожу отмечались отдельные мелкие фолликулярные папулы. На коже разгибательных поверхностей обоих коленных суставов фолликулярные папулы тесно сгруппированы и образовали сливные очаги размером до 9 см; местами папулы были расположены линейно (положительный феномен Кебнера). В этой области выделялись единичные элементы более крупных размеров (до 3 мм) синюшной окраски с приплюснутой вершиной. На коже голеней и тыльной поверхности стоп папулы крупные (3-5 мм), застойные, синюшно-коричневого цвета, с приплюснутой поверхностью по типу lichen ruber obtusus. В области нижней трети правой голени такие высыпания образовали сливное поражение, циркулярно охватывающее нижнюю конечность по типу носка (рис. 2). На боковой поверхности языка слева скудные высыпания, представленные мелкими папулами белого цвета, частично слившимися в дугообразный элемент размером 6 мм.

Отмечалась стойкая разлитая гиперемия кожи лица с множественными мелкими телеангиэктазиями, особенно в области носа и щек. Веки отечны, гиперемированы, имелась гипертрофия правого верхнего века. В межресничных пространствах скопление мелких беловатых чешуек. Склеры инъецированы. В височных областях отмечались участки кожи желтовато-белого цвета с радиальными и продольными бороздами кожи, формирующими фигуры ромбов. На коже предплечий и плеч многочисленные атрофические рубцы диаметром до 2,5 cм; на коже в области грудины - плотное возвышающееся безболезненное образование фииолетового цвета без кожного рисунка размерами 3,5 × 2 см. На фоне отечности и охряной пигментации кожи голеней видны расширенные и варикозно измененные подкожные вены. Утолщение и изменение цвета всех ногтевых пластин пальцев кистей рук и стоп различной степени выраженности (в большей мере на стопах), множественные продольные полосы коричневого цвета.

При обследовании выявлены повышение СОЭ (25 мм/ч), уровня С-реактивного белка (9,30 мг/л), дислипидемия с повышенным коэффициентом атерогенности $(4,9)$; по данным ультразвукового исследования брюшной полости и почек - гепатомегалия, диффузное уплотнение печени, поджелудочной железы, деформация желчного пузыря, холестероз и застой желчи; снижение паренхиматозного индекса почек, умеренное уплотнение паренхимы почек. По данным ЭКГ - фибрилляция предсердий, нормосистолическая форма, частота сердечных со-

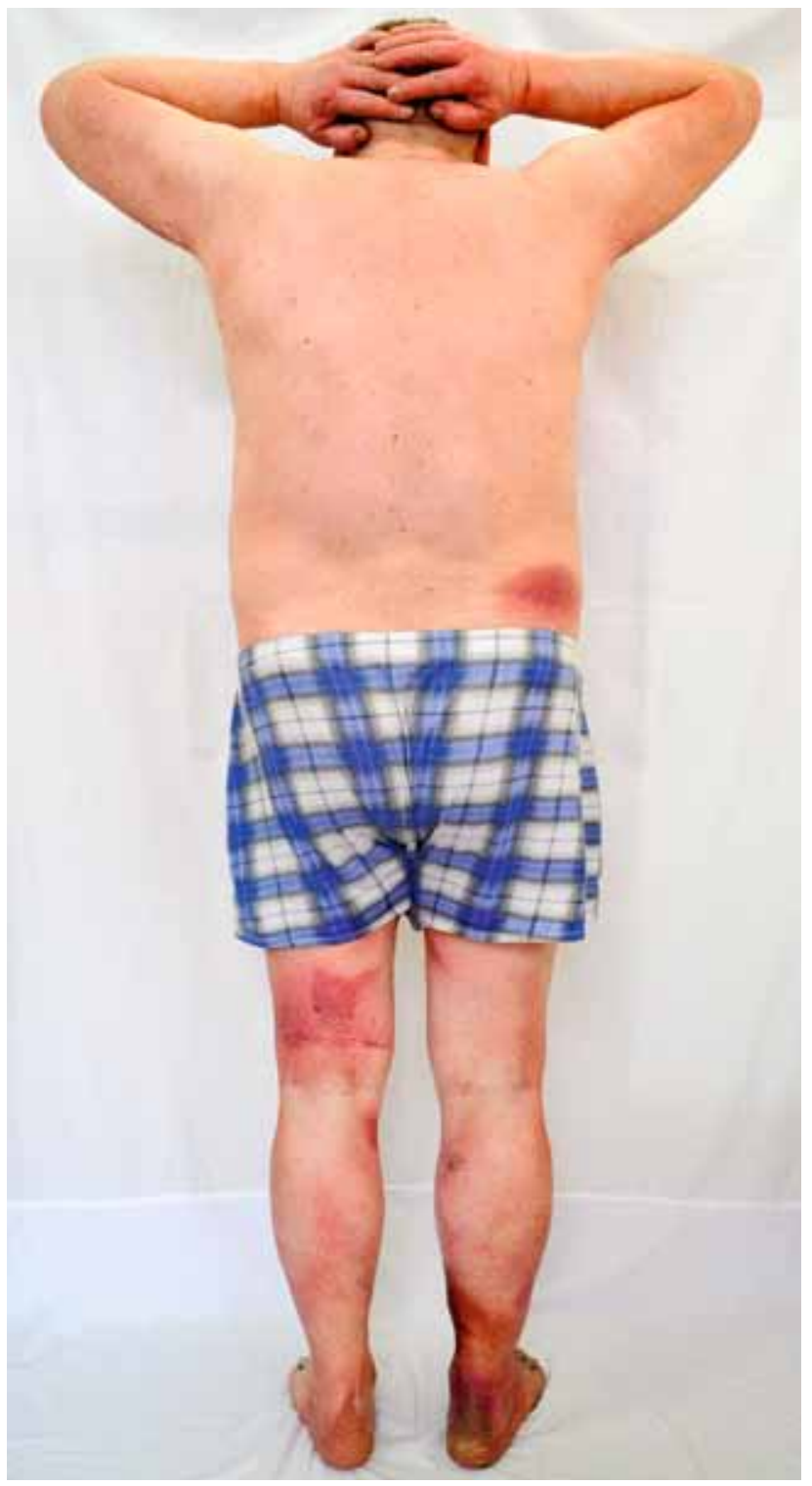

Асимметричные сливные поражения. На ко-
же поясницы справа - фриолетовая бляшка
с нечеткими границами без атрофии. На бе-
Рис. 2.
дре - красно-коричневые участки (распро-
странение очагов с передней поверхности
бедер). В нижней трети правой голени и сто-
пы - сливное поражение по типу носка

кращений 88 в минуту, гипертрофия левого желудочка. Микологическое исследование чешуек ногтевых пластин I пальцев стоп - обнаружены мицелий и споры.

Для патоморфологического исследования взяты четыре биоптата с различных участков поражения кожи: над левым коленным суставом, правого бедра, 
на правой ладони, а также фриолетовой бляшки в поясничной области.

І. Патоморфологическое исследование фолликулярной папулы на коже над левым коленным суставом: гиперкератоз, устья волосяных фолликулов резко расширены, заполнены роговыми массами - роговой пробкой. Эпидермис не утолщен. Вакуолизация клеток базального слоя. У нижнего полюса устья волосяного фолликула - густой полосовидный лимфоцитарный инфильтрат. Верхняя граница инфильтрата и нижняя граница эпидермиса - устья волосяного фолликула «размыты» клетками инфильтрата.

Заключение: красный плоский лишай, фолликулярная фрорма.

II. Патоморфологическое исследование участка на коже правого бедра в очаге пойкилодермии: диффузный гиперкератоз, в том числе выраженный фолликулярный. Волосяные фолликулы расширены, заполнены роговыми массами. Стенки устья волосяных фолликулов с выраженным зернистым слоем (4-6 рядов). На остальных участках - выраженная атрофия эпидермиса. Экзоцитоз. Диффрузный полосовидный инфильтрат в верхнем отделе дермы, вплотную примыкающий к эпидермису, нижняя граница которого «размыта» клетками инфрильтрата, состоящего преимущественно из лимфоцитов. Встречаются гистиоциты, фибробласты. Множество мелких сосудов в полосовидном инфильтрате. По краям инфильтрата - сосуды более крупные, просвет расширен.

Заключение: красный плоский лишай, фолликулярная форма с атрофией эпидермиса.

III. Патоморфологическое исследование участка кожи на правой ладони: мощный диффузный гиперкератоз, неравномерное утолщение зернистого слоя, гипергранулез (до 5 рядов). Эпидермис пролиферирован. Вакуолизация клеток базального слоя. Папилломатоз. Под эпидермисом - слабый полосовидный инфильтрат, состоящий преимущественно из лимфоцитов. В нижних отделах дермы - потовые железы.

Заключение: красный плоский лишай, типичная форма (связь с потовыми железами не обнаружена).

IV. Патоморфологическое исследование фиолетовой бляшки в поясничной области: гиперкератоз, в центре препарата остроконечный фролликулярный «шипик», образованный мощным гиперкератозом. Волосяной фолликул не обнаружен (не попал в срез). Эпидермис пролиферирован. Непосредственно под эпидермисом - полосовидный инфильтрат, состоящий из лимфоцитов, с явлениями экзоцитоза в эпидермисе. Граница между эпидермисом и полосовидным инфильтратом «размыта».

Заключение: красный плоский лишай, фолликулярная фрорма.

Клинический диагноз: распространенный красный плоский лишай, фолликулярная форма, прогрессирующая стадия.
Сопутствующие заболевания: розацеа, эритематозная стадия; актинический эластоз кожи лица; келоидный рубец в области груди; дистально-латеральный онихомикоз I пальцев стоп.

Гипертоническая болезнь II стадии, ожирение II степени (индекс массы тела 39), дислипидемия, риск сердечно-сосудистых осложнений 4-й степени. Фибрилляция предсердий, нормосистолическая фрорма. Варикозная болезнь вен нижних конечностей, хроническая венозная недостаточность. Начальная катаракта, пресбиопия. Гипертоническая ангиопатия сетчатки. Хронический мейбомиевый блефрарит, вне обострения.

Лечение:

tab. Hydroxychloroquine sulfatis 200 мг 2 раза в день циклами по 10 дней с перерывом 3 дня, общей суммой 6 циклов;

Sol. Natrii thiosulfatis $30 \%-10$ мл + Sol. $\mathrm{NaCl}$ 0,9\% - 200 мл внутривенно, капельно, № 10;

ланолиновый крем 2 раза в день.

Особенности случая:

1. Дебют заболевания на коже нижних конечностей.

2. Необычные клинические проявления, возникшие на отдельных участках кожи при длительном существовании тесно сгруппированных фолликулярных папул в процессе их эволюции:

- распространенные симметричные очаги на бедрах по типу пойкилодермии с мелкоячеистым строением, образованные за счет чередования мелких депигментированных участков атрофии, с участками более выраженной красно-коричневой окраски кожи и телеангиэктазиями;

- слабоинфильтрированная, внешне гомогенная фиолетовая бляшка в области поясницы справа без признаков атрофии.

3. Отсутствие поражения кожи волосистой части головы, подмышечных и лобковой областей, а также выраженных изменений на слизистой оболочке рта.

4. Распространенные высыпания не сопровождались зудом и не влияли на общее самочувствие больного.

5. Длительное прогрессирующее течение заболевания (более десяти лет) без периодов полной ремиссии.

Больной был представлен нами на заседании научного дерматологического общества им. В. М. Тарновского 31.03.2015.

\section{Заключение}

Фолликулярную форму красного плоского лишая в отечественной и зарубежной литературе рассматривают в основном как декальвирующий дерматоз. Пациенты, у которых диагностируют данную фрорму заболевания, чаще обращаются к дерматологам по поводу прогрессирующей рубцовой алопеции волосистой части головы, поскольку высыпания на гладкой коже 
обычно не вызывают субъективных ощущений, а выпадение пушковых волос на туловище и конечностях остается незамеченным.

Ряд дерматологов отмечал, что при фолликулярном красном плоском лишае рубцовая алопеция развивается не только на волосистой части головы, но и на любом другом участке кожи, где имеются длинные, щетинистые или пушковые волосы [6, 8, 9, $12,13,19]$. Однако лишь на волосистой части голо- вы атрофрическое облысение клинически выражено, а на других участках пораженной кожи клинических проявлений атрофии кожи или атрофического облысения не обнаруживают. На примере описанного нами наблюдения больного показано, что в некоторых случаях атрофические очаги образуются и на гладкой коже в местах длительно существующих, тесно сгруппированных (с образованием бляшек) фолликулярных папул lichen ruber follicularis.

\section{Литература}

1. Bazin E., Delahaye E. Leçons théoriques et cliniques sur les affections génériques de la peau. 1862; 2: 323-325.

2. Hebra F. Virchows Handbuch der speziellen Pathologie und Therapie. 1862; Bd. 3; 321.

3. Wilson E. On leichen planus. J Cutan Med Dis Skin 1869; 3: 117-132.

4. Berenbejn B.A. Lichens. In: Skin and venereal diseases. A Guide for Doctors: in 4 v. Skripkin Ju.K. edition. M: Medicine 1995; 2: 121 127. [Беренбейн Б.А. Лихены. В кн. Кожные и венерические болезни. Руководство для врачей: в 4 т. Под ред. Ю.К. Скрипкина. М: Медицина 1995; (2): 121-127.]

5. Pringle J.J. Folliculitis decalvans et atrophicans: report of a case. Br J Dermatol 1905; 17 : 77-78.

6. Little E.G. Br J Derm 1915; 27: 183-185.

7. Piccardi G.G. Cheratosi spinulosa del capillizio a suoi rapporti con al pseudo-pelade di Brocq. Ital Mal ven (Milano) 1914; 49: 416_422.

8. Little E.G. Lichen Spinulosus with Folliculitis Decalvans. Proc R Soc Med 1921; 14 (Dermatol Sect): $67-68$

9. Little E.G. Lichen Plano-Pilaris. Proc R Soc Med 1926; 19 (Dermatol Sect): 58.
10. Silver H., Chargin L., Sachs P.M. Follicular lichen planus (lichen planopilaris). (AMA) Arch Derm Syphilol 1953; 4: 346-354.

11. Mashkillejson L.N. Individual dermatology. M: Medicine 1965; 135-137. [Машкиллейсон Л.Н. Частная дерматология. М: Медицина 1965; 135-137.]

12. Traub E.F. Lichen Planus et Acuminatus Atrophicans (Folliculitis Decalvans et Lichen Spinulosus of Little). (AMA) Arch Derm Syphilol 1937; 36: 888.

13. Raznatovskij I.M., Rodionov A.N. About Piccardi - Lassueur - Little syndrome. Vestn dermatol venerol 1978; 4: 54—56. [Разнатовский И.М., Родионов А.Н. 0 синдроме Piccardi - Lassueur — Little. Вестн дерматол венерол 1978; (4): 54—56.]

14. Moshkalova I.A., Miheev G.N., Sokolovskij E.V. Lichen ruber follicularis decalvans (review of literature and clinical observations). Part II. Sovr probl dermatoven immunol I vracheb kosmetol 2011; 4: 74-80. [Мошкалова И.А., Михеев Г.Н., Соколовский Е.В. Фолликулярный декальвирующий красный лишай (обзор литературы и собственные наблюдения). Часть II. Совр пробл дерматовен иммунол и врачеб косметол 2011; (4): 74—80.]
15. Pai V.V., Kikkeri N.N., Sori T. Graham Little Piccardi - Lassueur Syndrome: An Unusual Variant of Follicular Lichen Planus. J Trichology 2011; 3 (1): 28-30.

16. Gupta S.N., Palceski D. Lichen Planopilaris Presenting as Truncal Alopecia: A Case Presentation and Review of the Literature. Cutis 2003; 72 : 63-66.

17. Molochkov V.A., Sukhova T.E., Molochkova Yu.V. Clinical features of lichen ruber planus. Klin dermatol venerol 2013; 4: 34-42. [Молочков В.А., Сухова Т.Е., Молочкова Ю.В. Клинические особенности красного плоского лишая. Клин дерматол венерол 2013; (4): 34-42.]

18. Aravijskaja E.R., Miheev G.N., Moshkalova I.A., Sokolovskij E.V. Alopecia. Differential diagnosis. Therapy methods. Sokolovskij E.V. edition. SPb: SOTIS 2003; 91-94. [Аравийская Е.Р., Михеев Г.Н., Мошкалова И.А., Соколовский Е.В. Облысение. Дифференциальный диагноз. Методы терапии. Под. ред. Е.В.Соколовского. СПб: СОТИС 2003; 91—94.]

19. Feldman J. Lichen planus et acuminatus atrophicans: folliculitis decalvans et lichen spinulosa of Little. Arch Derm 1936; 34: 378—397.

об авторах:

Е.В. Соколовский - д.м.н., профрессор, зав. кафедрой дерматовенерологии с клиникой ГБОУ ВПО ПСПбГМУ им. академика И.П. Павлова

Г.Н. Михеев — к.м.н., доцент кафедры дерматовенерологии с клиникой ГБОУ ВПО ПСПбГМУ им. академика И.П. Павлова

П.А. Резцова — врач-интерн кафедры дерматовенерологии с клиникой ГБОУ ВПО ПСПбГМУ им. академика И.П. Павлова

\section{Конфликт интересов}

Авторы заявляют об отсутствии потенциального конфликта интересов, требующего раскрытия в данной статье 